\title{
Competitividade interna na bovinocultura de corte no Estado do Rio Grande do Sul
}

\author{
Internal competitiveness in beef cattle activity in the State of Rio Grande do Sul
}

\author{
Ricardo Pedroso Oaigen ${ }^{\mathrm{I}}$ Júlio Otávio Jardim Barcellos ${ }^{\mathrm{II}}$ Maria Eugênia Andrighetto Canozzi ${ }^{\mathrm{II}}$ \\ Luciana Fagundes Christofari ${ }^{\text {IV }}$ Jean Carlos dos Reis Soares ${ }^{\text {III }}$ Carine Oliveira Alves $^{\text {V }}$
}

\section{RESUMO}

O presente trabalho teve por objetivo identificar os principais fatores internos (custos, receitas, viabilidade técnico-econômica e uso de inovações tecnológicas) que afetam a competitividade da bovinocultura de corte em um sistema de produção de ciclo completo no Estado do Rio Grande do Sul. Os dados foram coletados durante o ano de 2008, a partir de reuniões mensais entre os meses de janeiro e dezembro. Posteriormente, os dados foram analisados em planilhas eletrônicas. Os custos foram subdivididos em desembolsados, operacionais e totais e as receitas por categoria e total. Dentre os custos avaliados, destacaram-se o custo de oportunidade da terra, mão-de-obra e suplementação animal, com valores de $19,9 \%, 18,3 \%$ e 13,6\%, respectivamente, em relação ao custo total. Foram calculados os principais indicadores financeiros e técnicos utilizados comumente em análise de sistemas de produção. As margens econômicas (bruta, operacional e líquida), assim como a lucratividade $e$ rentabilidade sobre o patrimônio líquido, foram positivos, o que demonstra a viabilidade econômica da atividade. Ao mesmo tempo, indicadores técnicos, como a taxa de desfrute e a produtividade/ha, apresentaram valores satisfatórios. Dessa forma, pode-se concluir que os fatores internos avaliados foram extremamente competitivos para o sistema em questão.

Palavras-chave: pecuária de corte, gestão, sistemas de produção, custos, indicadores.

\section{ABSTRACT}

The present research aimed to identify the main internal factors (costs, income, techno-economic feasibility and technologic innovation use) which affect the beef cattle activity competitiveness in a complete cycle production system in the state of Rio Grande do Sul. The data was collected during the year of 2008 based on monthly meetings between the months of January and December. Later the data was analyzed in eletronic spreadsheets. The costs were subdivided in disbursed, operating and total costs and the income in category and total. Among the evaluated costs, the land opportunity cost, labor force and animal supplementation with values of $19.9 \%, 18.3 \%$, $13.6 \%$ respectively, can be pointed out in relation to total cost. The main financial and technical indicators commonly used in production systems analysis were calculated. The economic margins (gross, operating and net), as well as the profitability over the net worth were positive which show economic feasibility in the activity. At the same time, technical indicators as the output rate and the productivity/ha showed satisfactory values. Thus it can be concluded that the evaluated internal factors were very competitive for the studied system.

Key words: beef cattle, management, production system, costs, index.

\section{INTRODUÇÃO}

O Brasil, atualmente, é citado como um dos principais países emergentes, consequência de uma estabilidade econômica obtida na década de 90 . Dentro dessa conjuntura favorável, as exportações das commodities agropecuárias cresceram, anualmente, favorecendo o superávit primário da balança comercial.

'Faculdade de Medicina Veterinária, Universidade Federal do Pará (UFPA), Belém, PA, Brasil.

IDepartamento de Zootecnia, Universidade Federal do Rio Grande do Sul (UFRGS), Av. Bento Gonçalves, 7712, 91540-000, Porto

Alegre, RS, Brasil. E-mail: julio.barcellos@ufrgs.br. Autor para correspondência.

IIIPrograma de Pós-graduação em Zootecnia, Faculdade de Agronomia, UFRGS, Porto Alegre, RS, Brasil.

${ }^{\text {IV }}$ Departamento de Zootecnia, da Universidade Federal de Santa Maria (UFSM), CESNORS, Palmeira das Missões, RS, Brasil.

${ }^{\vee}$ Curso de Medicina Veterinária, Universidade Federal do Pará (UFPA), Belém, PA, Brasil. 
No entanto, existem barreiras a serem vencidas, o empresário rural (produtor) necessita ser competitivo. Com isso, é fundamental que a empresa seja lucrativa e rentável, pois sem geração de renda se torna inviável a sustentabilidade econômica e social do agronegócio dentro da porteira (BUAINAIN \& BATALHA, 2007).

Competitividade passou a ser um conceito amplamente discutido nos diferentes setores econômicos, inclusive na cadeia produtiva da carne bovina (IEL/CNA/SEBRAE, 2000; LAMY et al., 2003). A definição mais utilizada na literatura para este termo refere-se à capacidade de uma empresa, seja esta rural ou urbana, de formular e implementar estratégias de concorrência, que lhe permitam ampliar ou conservar, de forma duradoura, uma posição sustentável no mercado (SILVA, 2001). Também se refere à capacidade de adaptação ao ambiente externo (mercado ou sistema econômico) e interno (sua organização) a fim de manter ou superar a sua participação no mercado (PORTER, 1990). A associação da inovação tecnológica e a capacidade empresarial e gerencial deve ser o insumo vital na busca pelo crescimento sustentável do setor primário(COSTAetal., 2005a; OAIGEN \& BARCELLOS, 2008).

A partir desse contexto, o objetivo do presente trabalho foi identificar fatores internos que afetam a competitividade da bovinocultura de corte em um sistema de produção característico de integração lavoura-pecuária no Rio Grande do Sul. Entre esses fatores, foram avaliados os custos de produção, a produtividade e a viabilidade técnico-econômica.

\section{MATERIAL E MÉTODOS}

A empresa rural utilizada no presente estudo localiza-se no Estado do Rio Grande do Sul, na região da Depressão Central. A propriedade trabalha com sistema de integração lavoura-pecuária, sendo que as atividades agrícolas desenvolvidas são o arroz e a soja, enquanto que as pecuárias são a bovinocultura de corte e a ovinocultura. A presente análise técnico-financeira refere-se, exclusivamente, à bovinocultura de corte.

O sistema de produção é baseado no ciclo completo - cria, recria e engorda - e também na produção de genética com comercialização de reprodutores (ventres e touros). O rebanho é composto por 2.114 animais, correspondendo a 1.380 unidades animais (1UA=450kg de peso vivo) distribuídos em 1.680ha. A formação de pastagem hibernal constitui-se de 300ha provenientes da agricultura e 200ha arrendados.

Em relação ao manejo nutricional, os animais são criados a pasto, que é constituído em grande parte por espécies nativas (campo natural - bioma Pampa) e pastagens cultivadas de azevém (Lolium multiflorum), aveia (Avena strigosa) e trevo-branco (Trifolium repens). Todas as categorias do rebanho recebem suplementação alimentar a base de macro e micronutrientes durante o ano. $\mathrm{O}$ manejo reprodutivo baseia-se no estabelecimento de uma temporada de 90 dias, nos meses de novembro a janeiro. Utiliza-se primeiramente a IATF (inseminação artificial em tempo fixo) e após é feito o repasse com touros.

Foram coletadas informações gerenciais em reuniões mensais durante o ano de 2008 . Posteriormente, o processamento dos dados e a análise dos resultados e dos indicadores técnico-financeiros foram realizados em planilhas eletrônicas de Microsoft Excel. Os seguintes fatores de competitividade interna foram avaliados: produtividade, custos de produção e indicadores técnicos e financeiros.

Segundo VIANA \& SILVEIRA (2009), para a realização e análise dos custos de produção, é necessária a escolha de uma sequência metodológica a fim de se chegar a um resultado comum. Sendo assim, buscou-se utilizar a metodologia utilizada pela CONAB (2007) e por FLORES et al. (2006), com algumas pequenas alterações, visando mensurar os custos de produção, por meio da quantificação do custo desembolsado, do custo operacional e do custo total.

Frente ao exposto acima, foram calculados os custos fixos (CF), os custos variáveis (CV), o custo de oportunidade da terra (COT) e do capital (COC), o custo desembolsado (CD), o custo operacional (CO) e o custo total (CT). Os CF englobaram os impostos, a mão-de-obra e a depreciação, sendo esta última calculada individualmente, para cada bem de inventário (benfeitorias, implementos, equipamentos, veículos e máquinas), baseado no método linear (depreciação = valor inicial - valor residual / vida útil). Para tanto, foi utilizado um valor constante ao longo dos anos para cada bem, não sendo feito o uso de uma taxa fixa, conforme descrito por FLORES et al. (2006).

Já os CV fazem referência à aquisição de animais, combustíveis, suplementação animal, sanidade, pastagens (fertilizantes, sementes e herbicidas), arrendamentos, manutenções, despesas administrativas, inseminação artificial, comissões, associações de raça e despesas diversas. O CD é obtido com base na soma do CF (sem depreciação) e do CV, enquanto que o CO é a soma do CF (com depreciação) e do CV e o CT por meio da soma do CF (com depreciação), CV, COT e COC.

A receita bruta $(\mathrm{RB})$ foi calculada a partir do valor total de vendas durante o ano de 2008 (touros, ventres, novilhos e vacas de descarte). Posteriormente, 
foram calculados indicadores técnicos e financeiros, conforme segue: produção animal de carne (PAC), a qual é obtida com o uso da seguinte fórmula: (vendas + autoconsumo + inventário de animais no final do ano) - (compra + morte + inventário de animais no início do ano); produtividade (PR), que é a relação entre a PAC e a área total; e a taxa de desfrute (TD), que é obtida pela relação entre o número de cabeças vendidas no final do período e o número de cabeças existentes no início do período, sendo o resultado multiplicado por 100.

Entre os indicadores financeiros, utilizouse: a margem bruta (MB), que é a receita - CD; a margem operacional (MO), obtida pela diferença da receita e CO; a margem líquida (ML), que é a receita - CT; a lucratividade (LUC), sendo calculada pela diferença entre a receita total e CT e, após, divisão deste resultado pela receita total; a rentabilidade do patrimônio líquido (RPL), obtida pela relação entre LUC e patrimônio líquido; o ponto de equilíbrio físico (PEF), que é a relação entre CF pela diferença da receita média por cabeça e do custo variável unitário; o ponto de equilíbrio monetário (PEM), obtido pela multiplicação entre PEF e receita média por cabeça; o custo médio de produção por hectare, por cabeça e por quilo produzido, que é custo total / área total, custo total / número de cabeças vendidas e custo total / produção anual de carne (kg), respectivamente; as receitas médias por hectare, por cabeça e por quilo produzido; e a margem líquida (ML) por hectare e por cabeça, obtida pela diferença entre receita por ha e custo por ha e receita média por cabeça e custo monetário (cab), respectivamente.

\section{RESULTADOS E DISCUSSÃO}

Na tabela 1, verificamos a composição dos custos de produção. Os principais itens de custos foram o COT (20\%), a mão-de-obra (18\%), a suplementação animal (14\%), as pastagens (7\%) e o arrendamento (6\%). O COT foi calculado de acordo com o valor de mercado para o arrendamento na bovinocultura de corte, sendo este de $3.000 \mathrm{~kg}$ de peso vivo por quadra de sesmaria $(87,7 \mathrm{ha})$. O valor total foi de $\mathrm{R} \$ 143.671,61$ ou $\mathrm{R} \$ 85,50$ ha $^{-1}$, valor este muito aquém do mercado em comparação a outras possibilidades de arrendamento para atividades agropecuárias desenvolvidas na região, como a soja (R\$ 450,00 ha-1). Deve-se destacar que, se fossem utilizados no cálculo do COT outras opções de arrendamento para a região em estudo, especialmente para a agricultura, a presente análise não apresentaria margem líquida positiva, devido ao alto valor deste indicador econômico.
Tabela 1 - Custos de produção fixos, variáveis e de oportunidade de um sistema de produção de ciclo completo na bovinocultura de corte, na Região Sul do Brasil, referente ao ano de 2008 .

\begin{tabular}{lll}
\hline 1. Custos Fixos & Valores (R\$) & $(\%)$ \\
\hline 1.1 Depreciação & $15.512,93$ & 2,16 \\
1.2 Impostos (ITR, CNA,...) & $8.582,74$ & 1,19 \\
1.3 Mão-de-Obra & $131.806,53$ & 18,31 \\
Subtotal 1 & $155.902,20$ & 21,66 \\
2. Custos Variáveis & Valores (R\$) & $(\%)$ \\
2.1 Administração & $34.495,00$ & 4,79 \\
2.2 Aquisição de animais & $8.190,00$ & 1,14 \\
2.3 Arrendamentos & $43.500,00$ & 6,04 \\
2.4 Associações de raça & $6.459,00$ & 0,90 \\
2.5 Combustíveis & $30.304,77$ & 4,21 \\
2.6 Comissões & $19.586,90$ & 2,72 \\
2.7 Diversos & $12.733,59$ & 1,77 \\
2.8 Fertilizantes & $38.238,00$ & 5,31 \\
2.9 Inseminação artificial & $21.255,40$ & 2,95 \\
2.10 Manutenção & $28.564,16$ & 3,97 \\
2.11 Sanidade animal & $22.136,00$ & 3,08 \\
2.12 Suplementação animal & $98.074,68$ & 13,62 \\
2.13 Sementes forrageiras & $15.680,00$ & 2,18 \\
Subtotal 2 & $379.217,50$ & 52,68 \\
3. Custos de Oportunidade & Valores (R\$) & $(\%)$ \\
3.1 Terra & $143.671,61$ & 19,96 \\
3.2 Capital & $41.048,93$ & 5,70 \\
Subtotal 3 & $184.720,54$ & 25,66 \\
\hline & & \\
& & \\
& &
\end{tabular}

Em relação ao COC, ele foi calculado pelo produto entre o custo desembolsado e uma alternativa de investimento, neste caso, a caderneta de poupança, que rendeu em 2008 cerca de 7,9\%, e possui o menor risco de mercado. CARVALHO et al. (2009), em um trabalho com pecuária de corte, mensuraram a COC a partir de uma taxa $6 \%$ do total do capital investido em benfeitorias, máquinas, animais e terra, ou seja, o rendimento que seria obtido caso o capital investido fosse aplicado em poupança, sendo que o valor totalizou 68,2\% do CT, demonstrando a importância da mensuração deste indicador financeiro. COSTA et al. (2008), em trabalho similar no estado do Mato Grosso do Sul, demonstraram a importância do custo de oportunidade através da mensuração dos juros em relação ao capital imobilizado na empresa rural, sendo que essa taxa representou $12,2 \%$ do CT.

Outro item de custos representativo foi a mão-de-obra, devido a uma política gerencial, sempre destacada pelo empresário, de valorização dos recursos humanos. Do montante deste item, a mão-de-obra fixa representou cerca de $65 \%$, com sete empregados permanentes recebendo, em média, $\mathrm{R} \$ 1.017,00$, sendo 
a relação empregado/hectare de 1/240. É importante destacar que a empresa rural possui um baixo nível de rotatividade de colaboradores, sendo que todos passam por capacitações técnicas periodicamente.

Os custos com as pastagens cultivadas referem-se aos fertilizantes $(5,3 \%)$, as sementes forrageiras $(2,2 \%)$ e aos herbicidas $(0,4 \%$ dos custos diversos). Os custos relacionados com a mão-de-obra e combustíveis não foram adicionados nesta análise, pois não foram direcionados ao item pastagens no momento do processamento das informações. $\mathrm{O}$ valor pago em arrendamentos $(\mathrm{R} \$ 43.500,00)$ refere-se a uma área de pastagens cultivadas (área de resteva de soja). Com isso, o arrendamento de pastagens hibernais, somados aos custos com fertilizantes e sementes forrageiras totalizou $13,53 \%$ do CT.

Sabendo da relevância econômica da implantação de pastagens em sistemas de produção, COSTA et al. (2009) avaliaram o impacto econômico da implantação de forrageiras cultivadas (gramíneas e leguminosas), o qual foi mensurado pelo produto do benefício econômico por hectare pela área de adoção da tecnologia. Foram computados os aumentos de produtividade e/ou redução de custos. O lançamento dessas forrageiras contribuiu para aumentar a sustentabilidade dos elos da cadeia produtiva da pecuária de corte, via diversificação de pastagens, aumento da produtividade e da renda, redução de insumos, geração de empregos e recuperação de áreas degradadas.

As receitas do sistema de produção totalizaram, no ano de 2008, R \$ 808.113,92, superando o CT de produção, o que, segundo FLORES et al. (2006), torna a atividade viável economicamente. Na análise das receitas por categoria animal, existe diferenciação acentuada na receita unitária dos touros ( $\mathrm{R} \$ 5.716,55)$, em consequência da agregação de valor (venda de genética) na comercialização de reprodutores. É importante ressaltar que neste sistema de produção a diferenciação de produtos é utilizada como uma forma de aumentar a competitividade da empresa pecuária.

A tabela 2 apresenta os principais indicadores financeiros e técnicos mensurados para a bovinocultura de corte. Em relação às margens - $\mathrm{MB}$, $\mathrm{MO}$ e ML -, todas foram positivas, consequentemente, esta empresa rural tende a apresentar sustentabilidade econômica no longo prazo. Em contraposição, COSTA et al. (2005b), em trabalho avaliando um sistema de produção modal (ciclo completo) no Estado do Rio Grande do Sul, com 1.200ha na Região da Campanha, relatam, na análise econômica, que apenas a MB foi positiva, sendo a MO e ML negativas. É importante

Tabela 2 - Indicadores financeiros e técnicos de um sistema de produção de ciclo completo na bovinocultura de corte, na Região Sul do Brasil, referente ao ano de 2008.

\begin{tabular}{|c|c|c|}
\hline 1. Indicadores Financeiros & Unidade & Valores \\
\hline 1.1 Custo desembolsado & $(\mathrm{R} \$)$ & $519.606,77$ \\
\hline 1.2 Custo operacional & $(\mathrm{R} \$)$ & $535.119,70$ \\
\hline 1.3 Custo total & $(\mathrm{R} \$)$ & $719.840,24$ \\
\hline 1.4 Margem bruta & $(\mathrm{R} \$)$ & $288.507,15$ \\
\hline 1.5 Margem operacional & $(\mathrm{R} \$)$ & $272.994,22$ \\
\hline 1.6 Margem líquida & $(\mathrm{R} \$)$ & $88.273,68$ \\
\hline 1.7 Lucratividade (em relação à margem líquida) & $(\%)$ & 10,9 \\
\hline 1.8 Rentabilidade (do patrimônio líquido) & $(\%)$ & 0,85 \\
\hline 1.9 Receita (por hectare) & $(\mathrm{R} \$)$ & 481,02 \\
\hline 1.10 Custo (por hectare) & $(\mathrm{R} \$)$ & 428,48 \\
\hline 1.11 Margem líquida (por hectare) & $(\mathrm{R} \$)$ & 52,54 \\
\hline 1.12 Receita (por quilo produzido) & $(\mathrm{R} \$)$ & 3,40 \\
\hline 1.13 Custo (por quilo produzido) & $(\mathrm{R} \$)$ & 3,03 \\
\hline 1.14 Receita (por cabeça) & $(\mathrm{R} \$)$ & $1.815,99$ \\
\hline 1.15 Custo (por cabeça) & $(\mathrm{R} \$)$ & $1.617,62$ \\
\hline 1.16 Margem líquida (por cabeça) & $(\mathrm{R} \$)$ & 198,37 \\
\hline 1.17 Ponto de equilíbrio físico & Cabeças & 162 \\
\hline 1.18 Ponto de equilíbrio monetário & $(\mathrm{R} \$)$ & $293.746,30$ \\
\hline 2. Indicadores Técnicos & Unidade & Valores \\
\hline 2.1 Taxa de desfrute & $(\%)$ & 21,1 \\
\hline 2.2 Produção anual de carne & (kg) & $237.488,00$ \\
\hline 2.3 Produtividade & $\left(\mathrm{kg} \mathrm{ha}^{-1}\right)$ & 141,36 \\
\hline
\end{tabular}

Ciência Rural, v.41, n.6, jun, 2011. 
enfatizar que o sistema avaliado não possuía integração com agricultura e nem produção de genética.

A LUC, calculada em relação à ML, foi de 10,9\% no período. Segundo FLORES et al. (2006), este indicador representa, em percentual, qual foi o lucro obtido em determinada atividade ou na empresa rural com a venda dos produtos desenvolvidos. A RPL ficou em $0,85 \%$, valor este considerado extremamente baixo devido ao alto imobilizado existente na bovinocultura de corte, principalmente no que se referem ao rebanho bovino, as terras e ao inventário de máquinas e benfeitorias.

Segundo a SCOT CONSULTORIA (2009), sistemas de produção de ciclo completo com aplicação crescente de tecnologia apresentaram uma rentabilidade média de 3,61\% no ano de 2008. A aplicação crescente de tecnologia é um dos determinantes da boa rentabilidade, e isso fica evidente na análise dos resultados financeiros de 2008, em que todas as fazendas de pecuária de corte avaliadas por esta empresa de consultoria, e que utilizaram tecnologias de produção, como melhorias nas pastagens, obtiveram retorno positivo em relação ao patrimônio.

ABREU et al. (2003) demonstram que o uso de tecnologias de produção simples e de baixo custo, como a implantação da estação de monta, impacta positivamente os sistemas de produção. Neste sentido, HEMBRY (1991) relata que as atividades produtivas devem ser manejadas dentro de um enfoque sistêmico. Tal abordagem se aplica a qualquer objetivo a ser alcançado, em especial, o de maximizar lucros. Os sistemas de produção de gado de corte são complexos e diversificados, não havendo fórmulas e nem recomendações únicas que possam ser largamente aplicados. Pelo contrário, cada produtor desenvolve seu sistema de produção, em que associa as suas metas com as condições de ambiente e de mercado.

Segundo LOBATO (2005), a pecuária de corte de ciclo completo é uma atividade em que o capital imobilizado é muito alto. Na maior parte dos casos, o rendimento isolado é muito baixo, o que torna o empreendimento dependente da escala. Entretanto, quando integrada com a agricultura, pode aumentar o giro de capital em curto espaço de tempo. BARCELLOS et al. (2004) relatam que sistemas de ciclo completo extensivos, semi-intensivos e intensivos, localizados na Região Sul do Brasil, apresentam, em média, uma rentabilidade anual de $1,7 \%, 2,6 \%$ e 3,9\%, respectivamente.

O PEF foi de 162 cabeças, sendo calculado considerando valores de R \$ 155.902,20, R \$ 1.815,99 e $\mathrm{R} \$$ 852,17, respectivamente para o custo fixo, preço unitário (receita média por cabeça) e custo variável unitário. Na presente análise, a quantidade de cabeças produzidas, entre novilhos, vacas de descarte, ventres e touros, foi de 445 animais, superando o ponto de equilíbrio. O PEM foi de R \$293.746,30, sendo calculado pelo produto do PEF pela receita por cabeça (média ponderada). Segundo CREPALDI (2006), este indicador é fundamental para a empresa identificar a quantidade mínima a ser produzida para que não ocorra prejuízo.

A PAC é um indicador técnico importante de ser calculado, pois não se refere apenas à produção obtida com as vendas e sim indica a real produção de carne obtida em um sistema de produção. A partir da PAC, calcula-se a PR real por hectare, que, no sistema em questão, foi de 141,36kg/ha, valor este considerado muito bom para sistemas de ciclo completo, assim como a TD que obteve um valor acima da média para sistemas de produção de ciclo completo.

\section{CONCLUSÃO}

O sistema de produção analisado apresentou viabilidade econômica e técnica, demonstrando que os fatores internos são competitivos para a bovinocultura de corte.

A ML, MO, MB, LUC e RPL foram positivos, o que comprova a viabilidade econômica da atividade. Ao mesmo tempo, indicadores técnicos, como a TD, a PAC e a PR, apresentaram valores acima da média em relação a empresas similares.

No entanto, é fundamental que outros trabalhos sejam realizados, buscando avaliar a competitividade sistêmica dos sistemas de produção existentes no Brasil. Essas análises devem também envolver os diferentes elos que formam a cadeia produtiva da carne bovina. Ao mesmo tempo, a análise da tipologia dos sistemas produtivos torna-se fundamental para que as ações precisas sejam executadas, visando ao aumento da rentabilidade e da produtividade das empresas rurais especializadas na bovinocultura de corte.

\section{REFERÊNCIAS}

ABREU, U.G.P. et al. Análise bioeconômica da introdução de período de monta em sistemas de produção de gado de cria na região do Brasil Central. Revista Brasileira de Zootecnia, v.32, n.5, p.1198-1206, 2003. Disponível em: <http:// www.scielo.br/pdf/rbz/v32n5/17903.pdf >. Acesso em: 17 ago. 2010. doi: 10.1590/S1516-35982003000500021.

BARCELLOS, J.O.J. et al. Bovinocultura de corte frente a agriculturização no Sul do Brasil. In: CICLO DE ATUALIZAÇÃO EM MEDICINA VETERINÁRIA, 11., 2004, Lages, SC. Anais... Lages: Centro Agroveterinário de Lages, 2004. p.13-30.

Ciência Rural, v.41, n.6, jun, 2011. 
BUAINAIN, A.M.; BATALHA, M.O. Cadeia produtiva da carne bovina (série agronegócios). Brasília: Ministério da Agricultura, Pecuária e Abastecimento, 2007. 86p. (Boletim Técnico, 8).

CARVALHO, T.B. et al. Custo de produção em pecuária de corte em 2009, no Pantanal de Aquidauaná (MS). Campo Grande: Embrapa Gado de Corte. 2009. 5p. (Comunicado Técnico, 77).

CONAB. Metodologia de cálculo de custos de produção, 2007. Disponível em: <http://www.conab.gov.br/conabweb/ download/safra/custosproducaometodologia.pdf $>$. Online. Acesso em: 20 jul. 2008.

COSTA, L.B. et al. Viabilidade econômica da atividade pecuária em propriedade de ciclo completo: uma simulação. In: CONGRESSO INTERNACIONAL DE CUSTOS, 9., 2005a, Florianópolis, SC. Anais... Florianópolis: UFSC, 2005a. (CDROOM).

COSTA, F.P. et al. Sistema e custo de produção de gado de corte no Estado do Rio Grande do Sul - Região da Campanha. Campo Grande: Embrapa Gado de Corte, 2005b. 10p. (Comunicado Técnico, 95).

COSTA, F.P. et al. Custos de produção de gado de corte em Mato Grosso do Sul - Setembro de 2007. Campo Grande: Embrapa Gado de Corte, 2008. 8p. (Comunicado Técnico, 111).

COSTA, F.P. et al. Avaliação dos impactos econômicos de quatro forrageiras lançadas pela Embrapa. Campo Grande: Embrapa Gado de Corte, 2009. 27p. (Documentos, 174).

CREPALDI, J.A. Contabilidade Rural: uma abordagem decisional. São Paulo: Atlas, 2006. 340p.

FLORES, A.W. et al. Gestão rural. Porto Alegre: Ed. dos Autores, 2006. 328p.

HEMBRY, G. Management of beef cattle production. 1991. Disponível em: <http://gnv.ifas.ufl.edu/animal/short91/ hembry.htm>. On line. Acesso em: 17 ago. 2010.
IEL/CNA/SEBRAE. Estudo sobre a eficiência econômica e competitividade da cadeia agroindustrial da pecuária de corte, 2000. Disponível em <http:// www.biblioteca.sebrae.com.br/>. Online. Acesso em: 20 mar. 2009.

LAMY, V.C. et al. The competitiveness of the beef sector in Argentina and Canada. Agricultural and Agri-Food Canada, 2003. Disponível em: <http://ageconsearch.umn.edu/ bitstream/53768/3/argen_can_f.pdf $>$. Online. Acesso em: 15 abr. 2009.

LOBATO, J.F.P. Diversificação e agilidade são os maiores desafios. Piracaba: USP/ESALQ, Visão Agrícola Bovinos, 2005. 2p. (Boletim Técnico, 3).

OAIGEN, R.P.; BARCELLOS, J.O.J. Gerenciamento e custo de produção. In: MOURA, J.A. et al. Programa de atualização em medicina veterinária. Porto Alegre: ARTMED, 2008. p.51-88.

PORTER, M.E. Vantagem competitiva: criando e sustentando um desempenho superior. Rio de Janeiro: Campus, 1990. 563p.

SCOT CONSULTORIA. Site de informações pecuárias. Bebedouro: Scot Consultoria, 2009. Disponível em: <http:// www.scotconsultoria.com.br>. Online. Acesso em: 28 maio, 2009.

SILVA, C.L. Competitividade e estratégia empresarial: um estudo de caso da indústria automobilística brasileira na década de 1990. Revista da FAE, Curitiba, v.4, n.1, p.35-48, 2001. Disponível em: <http://www.fae.edu/publicacoes/pdf/revista_da_fae/ fae_v4_n1/competitividade_e_estrategia.pdf $>$. Acesso em: 15 fev. 2009.

VIANA, J.G.A.; SILVEIRA, V.C.P. Análise econômica da ovinocultura: um estudo de caso na Metade Sul do Rio Grande do Sul, Brasil. Ciência Rural, Santa Maria, v.39, n.4, p.11871192, 2009. Disponível em:<http://www.scielo.br/pdf/cr/v39n4/ a136cr228.pdf $>$. Acesso em: 25 set. 2009. doi: 10.1590/ S0103-84782009005000030. 